\title{
An Investigation of the Cover, Copy, and Compare Method for EFL Spelling
}

\author{
Keith M. Graham \\ New Taipei City, Taiwan, R.O.C.
}

\begin{abstract}
This research study examines the effects of the cover, copy, and compare (CCC) spelling study method on Taiwanese junior high students enrolled in an upperbeginner level English as a Foreign Language course. Data were collected on the change in scores between four tests. Test results show a slight difference between a control group and experimental group in gains of correctly spelled words between the pretest and the posttest. However in two delayed posttests, the experimental group retained their gains slightly better than the control group. The results suggest that CCC may help English learners retain studied spelling words, but further research is required to confirm its effectiveness.
\end{abstract}

\section{The Importance of Spelling}

Spelling is an important skill for English Language Learners (ELLs). Strong skills in spelling have been said to make both reading and writing easier, allowing the student to focus on ideas rather than on letters in a word (Joshi, Treiman, Carreker, \& Moats, 2008-2009). Spelling, whether good or bad, can often influence perceptions of other people toward the speller since spelling is seen as a "serious social error, making a person, at least, illiterate if not outright ignorant" (Cronnell, 1979, p. 202). Poorly spelled words can lead to frustration and embarrassment for English language learners (Joshi et al., 2008). With the availability of technologies such as spell check, one may easily dismiss the idea that strong spelling skills are needed. However, Jones (2009) reminds us that the technology is not a complete solution, with the user still having to pick the correct word from a list of suggestions.

To increase the ease of literacy skills and to avoid social criticism, learning to spell correctly is important. Therefore, teachers of ELLs must be equipped with solid pedagogical practices for spelling to help their students succeed. This paper will examine the effects of a spelling study method called Cover, Copy, and Compare (hereafter CCC) on upper-beginner EFL junior high school students' spelling ability in terms of initial success and retention of correctly spelled words. It begins with a survey of the literature that documents attitudes toward spelling instruction in EFL contexts and the successes of CCC with a variety of student populations. It then describes the methods of the current study on CCC conducted with junior high school EFL students in Taiwan. The paper ends with a discussion of the effects of CCC and a call for further study. 


\section{Literature Review}

\section{Spelling Instruction in EFL Contexts}

The teaching of spelling is a contested issue in the field of foreign language teaching (Pérez Cañado, 2006). The debate revolves around the issue of whether to allow spelling to be learned through explicit instruction or to be learned implicitly. Researchers such as Krashen (1989) present evidence that suggests adequate exposure to text will result in spelling ability. However, Shemesh and Waller (2000) suggest that a more explicit approach is necessary. Some such as Nation (2009) advocate for a balanced approach. This lack of clear consensus may be why researchers of EFL tend to focus on other areas such as vocabulary and grammar rather than spelling (Mahmoud, 2013). Although the debate continues, Graham and Santangelo's (2014) meta-analysis resulted in support for explicit spelling instruction.

\section{What is Cover, Copy, and Compare?}

CCC is a study method used to help students improve their skills in spelling (Skinner, McLaughlin, \& Logan, 1997), math (Skinner, Bamberg, Smith, \& Powell, 1993), geography (Skinner, Belfiore, \& Pierce, 1992), sight word recognition (Conley, Derby, Roberts-Gwinn, Weber, \& McLaughlin, 2004), science (Smith, Dittmer, \& Skinner, 2002) and foreign language acquisition (Carter, Wong, \& Mayton, 2013). CCC requires three steps. First, the student looks at a stimulus to be mastered, such as a written word, a mathematics problem with an answer, or another item relevant to the subject. Second, the student covers the stimulus from step one and makes a response either orally or in written form. Third, the student looks at the original stimulus item and compares it with the response (Skinner, McLaughlin, \& Logan, 1997, p. 296). Whether an additional step is required depends on the response. If correct, the student repeats the process for the next academic stimulus. If incorrect, the student corrects the mistake, redoes the CCC process, or engages in another type of practice.

\section{Research Findings on CCC}

Research on CCC for spelling has been conducted on many different age groups and classroom situations. The results of studies have shown CCC to be helpful with improving the spelling of elementary (Darrow, McLaughlin, Derby, \& Johnson, 2012; Erion, Davenport, Rodax, Scholl, \& Hardy, 2009) and middle school students (Hollingsworth, Keith, McLaughlin, \& Derby, 2012; Poindexter, McLaughlin, Derby, \& Johnson, 2012). A study by Merritt, McLaughlin, Weber, Derby, and Barretto (2012) concluded that CCC produces positive results for students classified as at-risk. Furthermore, Cordes, McLaughlin, Derby, and Higgins (2012) reported positive results of using CCC with an elementary student with autism. Poindexter, McLaughlin, Derby, and Johnson (2012) studied a seventh-grade male with learning disabilities and a study by Hollingsworth, Keith, McLaughlin, and Derby (2012) found that CCC was also effective for a seventh-grade male with severe behavior disorders. As for high school, Carter, McLaughlin, Derby, Schuler, and Everman (2011) used CCC to help increase the spelling accuracy for four high school students diagnosed with severe behavior disorders. These studies demonstrate CCC's versatility in many classroom settings.

Although these mostly single-case and small-group studies have suggested that CCC alone facilitated increases in spelling ability, Membrey, McLaughlin, Derby, and Antcliff's (2011) study of three middle-school students revealed that adding steps to CCC can increase its effectiveness. Although the researchers found that all three students improved after implementation of CCC, for one student, the researchers added copying and spelling out loud to the procedure. Following the modification, the student scored perfect scores on the last three spelling tests. 
Although the effects of CCC have been documented for many age groups and student types, no studies were found during a search of the literature that studied CCC's effects on EFL students. In one recent study, Carter, Wong, and Mayton (2013) studied the use of CCC in a Spanish class by a 15-year-old student diagnosed with a learning disability. However, the focus of this study was on reading and translation, not spelling. CCC has been shown to be "effective for increasing performance across curricula, settings, and subjects" (Skinner, McLaughlin, \& Logan, 1997, p. 296), but the research currently lacks data to support its effectiveness with EFL students. This study fills this gap by testing the effects of CCC on EFL students.

\section{The Context}

\section{Methodology}

This study took place in an English as a Foreign Language junior high school classroom in northern Taiwan. The study was conducted with 18 seventh-grade Taiwanese students enrolled in an upper-beginner English class. All students in the class had studied English for varying periods of time prior to entering the school, but a spectrum of ability levels existed within the class. Using the Teachers of English to Speakers of Other Languages (2006) Levels of English Language Proficiency, student ability level ranged from Level 2 (Emerging), with ability to "communicate limited information in simple, everyday and routine situations by using memorized phrases, groups of words, and formulae," to Level 4 (Expanding), with language skills "adequate for most day-to-day communication needs" (Teachers of English to Speakers of Other Languages, 2006, p. 40).

\section{Data Collection: Spelling Tests}

The 18 seventh-grade EFL students were administered four identical spelling tests: a pretest, a posttest, and two delayed posttests, with intervals described below. All of the tests required the students to spell the same 10 words (see Appendix A). These words were taken from the unit they were covering in the course reading textbook as required by the school's course syllabus. For all tests, the teacher dictated each word twice and the students wrote the words on the test paper. Scores on each test were out of 10 and 1 point was given for each correctly spelled word. The target score on the tests was 7 or higher, which would be considered passing.

The pretest was given before any instruction had occurred and was used to gauge the students' prior knowledge of words. Following the pretest, the students were divided evenly into two groups: nine in a control group and nine in an experimental group. These groups were based on students' pretest scores, with the goal of having an even balance of spelling ability in both groups.

Seven days following the pretest, a posttest was given. Immediately prior to the administering of the posttest, students in the experimental group were given a CCC study grid with five columns (see Appendix B). Students were instructed to look at the first column with the spelling word. Next, they wrote the word into the second column. Following that, students covered the first two columns with their textbook. Without looking at the first two columns, the student wrote the word into the third column from memory. The students then removed the textbook from the first two columns and compared their spelling in the third column. If their spelling was correct, students put a checkmark in the fourth column and moved on to the next word. If their spelling was incorrect, students wrote the word one more time in the final column without covering the other columns. The experimental group was allowed to work through the CCC study grid at their own pace and was not given any time restrictions. While the experimental group completed the CCC study grid, the control group was instructed to study their vocabulary list quietly in preparation for the test. 
At an interval of 5 days and 19 days following the posttest, delayed posttests were administered in the same way as the posttest in order to gauge retention. These intervals were chosen based on Pimsleur's (1967) graduated interval recall schedule, but adapted to the class meeting schedule (i.e., the 19th day was used as opposed to the 22 nd as called for by Pimsleur). Students were not explicitly informed, other than through the study consent form, that these tests would occur. Unlike the posttest, where CCC was administered to the experimental group and the control group studied independently, neither group of students was given any time prior to the tests to prepare. These delayed posttests were administered after the completion of the reading unit.

\section{Spelling Test: Pretest}

\section{Findings}

The pretest results showed that most of the 18 students were not familiar with the majority of the words prior to instruction. With the exception of two students who correctly spelled six and five words correctly out of ten, the majority of students were only able to spell two words or fewer on the pretest. Five students correctly spelled two words, six students correctly spelled one word, and five students were not able to spell any of the words correctly.

\section{Spelling Test: Posttest}

Results from the spelling tests show that the gain between the pretest and posttest for both the control and experimental group were similar. Both groups' highest score was ten words correct and both groups' lowest score was three words correct. The control group went from an average of 1.6 words correct on the pretest to an average of 7.3 words correct on the posttest with an average gain of 5.7 words. Similarly, the experimental group went from an average of 1.4 words correct on the pretest to an average of 6.9 words correct on the posttest with an average gain of 5.5 words.

Table 1

Control Group Scores

\begin{tabular}{|c|c|c|c|c|}
\hline Participant & Pretest & Posttest & $\begin{array}{c}\text { Delayed Posttest } \\
1\end{array}$ & $\begin{array}{c}\text { Delayed Posttest } \\
2\end{array}$ \\
\hline C1 & & & 1 & 1 \\
\hline C2 & 0 & 10 & 2 & 0 \\
\hline C3 & 1 & 5 & 3 & 1 \\
\hline C4 5 & 1 & 7 & 4 & 4 \\
\hline C6 & 0 & 3 & 4 & 3 \\
\hline C7 & 1 & 10 & 5 & 7 \\
\hline C8 & 2 & 7 & 5 & 8 \\
\hline C9 & 2 & 8 & 5 & 9 \\
\hline
\end{tabular}

Note: The highest possible score for all spelling tests is 10 . 


\section{Table 2}

Experimental Group Scores

\begin{tabular}{|c|c|c|c|c|}
\hline Participant & Pretest & Posttest & Delayed Posttest & Delayed Posttest \\
& & & 1 & 2 \\
\hline E1 & 2 & 9 & 7 & 5 \\
\hline E2 & 0 & 3 & 2 & 4 \\
\hline E3 & 1 & 6 & 4 & 6 \\
\hline E4 & 2 & 7 & 6 & 5 \\
\hline E5 & 0 & 7 & 5 & 9 \\
\hline E6 & 2 & 8 & 6 & 6 \\
\hline E8 & 1 & 9 & 5 & 8 \\
\hline E9 & 5 & 10 & 10 & 1 \\
\hline
\end{tabular}

Note: The highest possible score for all spelling tests is 10 .

\section{Spelling Test: Delayed Posttests}

Although the two groups were similar in their gains between the pretest and the posttest, there was a difference in the loss of words between the posttest and the two delayed posttests with the experimental group exhibiting slightly better retention. The control group went from an average of 7.3 words correct on the posttest to an average of 4.3 words correct on the first delayed posttest, an average loss of three words. The average dropped slightly to 4.1 for the second delayed posttest. In contrast, the experimental group went from an average of 6.9 words correct on the posttest to an average of 5.2 words correct on the first delayed posttest with an average loss of 1.7 words. The average remained the same, 5.2, with a slight change in the standard deviation for the second delayed posttest.

\section{Conclusion}

\section{Outcomes}

Based on the scores from the spelling pretest, there was only a slight difference between the experimental group and the control group. Although there was an increase in correctly spelled words from pretest to posttest, the control group who spent time independently studying the list produced comparable results to the CCC group.

However, the delayed posttests revealed some difference in losses in retention incurred between the experimental group and the control group. The numbers suggest that CCC helped the students retain words slightly better than the control group in both delayed posttests. Although both groups' scores declined, the control group declined slightly more than the experimental group for the first delayed posttest with a slight additional decline after the second delayed posttest. In contrast, the experimental group declined less for the first delayed posttest and maintained their average for the second delayed posttest.

\section{Limitations}

There were a few limitations to this study. First, this study was conducted with only one set of words. Questions remain about the effectiveness of CCC for EFL students if multiple sets were considered. It is feasible that the use of CCC over time with a larger cumulative list of words may produce better results. The effectiveness of CCC with more words tested warrants further research.

Another limitation is the size of the group studied. With only eighteen students involved in the study, nine in each group, the size of the group is not large enough to definitively make 
conclusions about the implications for the larger population of EFL students. Future studies using larger groups of EFL students in different contexts are required to determine the effectiveness of CCC with EFL students.

\section{Implications}

This paper explores the effects of the spelling study method Cover, Copy and Compare. As revealed in the literature review, CCC has been shown to be a successful method with a variety of populations, yet the EFL context has not been thoroughly explored to date. Most current EFL spelling research focuses on error analysis, largely ignoring the research area of spelling instructional methods (Mahmoud, 2013). To the knowledge of the author, this study is the first to explore the CCC spelling teaching method in an EFL context and adds to the sparse research on EFL spelling instructional methods. Because of the importance of spelling for EFL students, more studies on CCC and other EFL spelling instructional methods are needed.

Although the scores of the experimental group did not rise substantially above the control group, the retention data suggests that CCC may still be useful in the EFL classroom. Fountas and Pinnell (2000) suggest a weekly sequence of spelling activities that includes CCC as one of the activities. Coupled with the additional spelling exercises that could help raise initial spelling ability, CCC could potentially be effective in helping to retain learned spelling words. However, further study would be required to confirm this assertion.

Unfortunately, the study did not produce the desired rise in EFL spelling scores for the group of EFL junior high students in the study, and questions still remain on the effectiveness of CCC on EFL spelling achievement. Further study is required to confirm these findings. If CCC is found by other studies to be ineffective with EFL students, further analysis would be required to determine why it had been successful with other populations and not with English language learners.

\section{Author Note}

Keith M. Graham, New Taipei City, Taiwan, R.O.C.

Keith M. Graham currently teaches at a private school in New Taipei City, Taiwan where he is the professional development coordinator for the international department and a junior high school EFL teacher. Mr. Graham holds a Master of Education in international literacy from Sam Houston State University.

Correspondence concerning this article should be addressed to Keith M. Graham. E-mail: keith@keithmgraham.com 


\section{References}

Carter, M. A., McLaughlin, T. F., Derby, K. M., Schuler, H., \& Everman, J. (2011). Differential effects of cover, copy, and compare in spelling with four high school students with severe behavior disorders. Academic Research International, 1(1), 43-51.

Carter, S. L., Wong, C.-Y., \& Mayton, M. R. (2013). Enhancing foreign language competency using the cover, copy, compare technique: An exploratory evaluation. Education and Treatment of Children, 36(2), 105-116. http://dx.doi.org/10.1353/etc.2013.0010

Conley, C. M., Derby, K. M., Roberts-Gwinn, M., Weber, K. P., \& McLaughlin, T. F. (2004). An analysis of initial acquisition and maintenance of sight words following picture matching and copy, cover, and compare teaching methods. Journal of Applied Behavior Analysis, 373), 339-350. http://dx.doi.org/10.1901/jaba.2004.37-339

Cordes, C. I., McLaughlin, T. F., Derby, K. M., \& Higgins, S. (2012). Implementing and evaluating cover, copy, and compare spelling for a primary student with autism: A case report. Academic Research International, 2(3), 271-276.

Cronnell, B. (1979). Spelling English as a second language. In M. Celce-Murcia \& L. McIntosh (Eds.), Teaching English as a Second or Foreign Language (pp. 202-214). Rowley, MA: Newbury House.

Darrow, D., McLaughlin, T. F., Derby, K. M., \& Johnson, K. (2012). Using cover, copy, and compare spelling with and without timing for elementary students with behavior disorders. International Electronic Journal of Elementary Education, 4(2), 417-426.

Erion, J., Davenport, C., Rodax, N., Scholl, B., \& Hardy, J. (2009). Cover-copy-compare and spelling: One versus three repetitions. Journal of Behavioral Education, 18(4), 319-330. http://dx.doi.org/10.1007/s10864-009-9095-4

Fountas, I. C., \& Pinnell, G. S. (2000). Guiding readers and writers: Teaching, comprehension, genre, and content literacy. Portsmouth, $\mathrm{NH}$ : Heinemann.

Graham, S., \& Santangelo, T. (2014). Does spelling instruction make students better spellers, readers, and writers? A meta-analytic review. Reading and Writing, 2799), 1703-1743. http://dx.doi.org/10.1007/s11145-014-9517-0

Hollingsworth, E., Keith, M., McLaughlin, T. F., \& Derby, K. M. (2012). The use of cover, copy, and compare to improve spelling with a middle school student in a behavior intervention classroom. Academic Research International, 2(3), 302-307.

Jones, S. (2009). The importance of spelling. Retrieved from http://www.spellingcity.com/importance-of-spelling.html

Joshi, R. M., Treiman, R., Carreker, S., \& Moats, L. C. (2008-2009). How words cast their spell. American Educator, 32(4), 6-16.

Krashen, S. (1989). We acquire vocabulary and spelling by reading: Additional evidence for the input hypothesis. The Modern Language Journal, 73(4), 440-464. http://dx.doi.org/10.1111/j.1540-4781.1989.tb05325.x

Mahmoud, A. (2013). Spelling errors of Arab learners of EFL: A two-way analysis. Perspectives (TESOL Arabia), 2011).

Membrey, A. D., McLaughlin, T. F., Derby, K. M., \& Antcliff, C. (2011). Use and modification of cover, copy, and compare in spelling for three middle-school students with multiple disabilities. International Journal of Social Sciences and Education, 1(4), 491-505.

Merritt, J., McLaughlin, T. F., Weber, K. P., Derby, K. M., \& Barretto, A. (2012). The effects of a copy, cover, compare practice procedure in spelling with four second-grade students: Generalization to weekly in classroom tests. International Journal of Advances in Psychology, 1(1), 1-5.

Nation, I. S. P. (2009). Teaching ESL/EFL reading and writing. New York, NY: Routledge.

Pérez Cañado, M. L. (2006). The effects of explicit spelling instruction in the Spanish EFL classroom: Diagnosis, development and durability. Language Awareness, 15(1), 20-37. http://dx.doi.org/10.1080/09658410608668847 
Pimsleur, P. (1967). A memory schedule. Modern Language Journal, 51(2), 73-75. http://dx.doi.org/10.1111/j.1540-4781.1967.tb06700.x

Poindexter, S., McLaughlin, T. F., Derby, K. M., \& Johnson, G. (2012). The effects of cover, copy, and compare on spelling accuracy with a middle school student with learning disabilities: A case report. International Journal of Basic and Applied Science, 1(2), 415422.

Shemesh, R., \& Waller, S. (2000). Teaching English spelling: A practical guide. Cambridge, UK: Cambridge University Press.

Skinner, C. H., Bamberg, H. W., Smith, E. S., \& Powell, S. S. (1993). Cognitive, cover, copy, and compare: Subvocal responding to increase rates of accurate division responding. Remedial and Special Education, 14(1), 49-56. http://dx.doi.org/10.1177/074193259301400107

Skinner, C. H., Belfiore, P. J., \& Pierce, N. (1992). Cover, copy, and compare: Increasing geography accuracy in students with behavior disorders. School Psychology Review, 27(1), 73-81.

Skinner, C. H., McLaughlin, T. F., \& Logan, P. (1997). Cover, copy, and compare: A selfmanaged academic intervention effective across skills, students, and settings. Journal of Behavioral Education, 73), 295-306. http://dx.doi.org/10.1023/A:1022823522040

Smith, T., Dittmer, K., \& Skinner, C. H. (2002). Enhancing science performance in students with learning disabilities using cover, copy, and compare: A student shows the way. Psychology in the Schools, 39(4), 417-426. http://dx.doi.org/10.1002/pits.10037

Teachers of English to Speakers of Other Languages. (2006). PreK-12 English language proficiency standards. Alexandria, VA: Teachers of English to Speakers of Other Languages. 


\section{Appendix A}

\section{Spelling Words}

1. crust

2. dangerous

3. destroy

4. direction

5. plate

6. powerful

7. pressure

8. fault

9. earthquake

10. tsunami 
Research

Appendix B

CCC Study Grid

\begin{tabular}{|l|l|l|l|l|}
\hline \multicolumn{1}{|c|}{ Spelling Word } & Copy & Cover + Copy & Compare & Correction \\
\hline crust & & & & \\
\hline dangerous & & & & \\
\hline destroy & & & & \\
\hline direction & & & & \\
\hline plate & & & & \\
\hline powerful & & & & \\
\hline pressure & & & & \\
\hline fault & & & & \\
\hline earthquake & & & & \\
\hline tsunami & & & & \\
\hline
\end{tabular}

